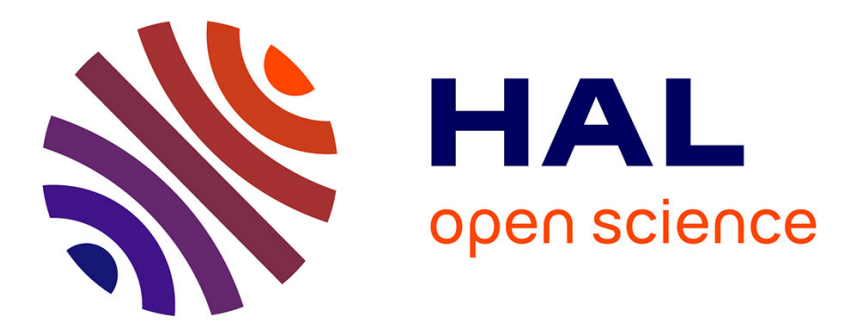

\title{
Flexible papers derived from polypyrrole deposited cellulose nanofibers for enhanced electromagnetic interference shielding in gigahertz frequencies
}

Deepu Gopakumar, Avinash Pai, Yasir Beeran Pottathara, Daniel Pasquini, Luís Carlos Morais, Abdul Khalil H.P.S., Ange Nzihou, Sabu Thomas

\section{To cite this version:}

Deepu Gopakumar, Avinash Pai, Yasir Beeran Pottathara, Daniel Pasquini, Luís Carlos Morais, et al.. Flexible papers derived from polypyrrole deposited cellulose nanofibers for enhanced electromagnetic interference shielding in gigahertz frequencies. Journal of Applied Polymer Science, 2021, 138 (16), pp.1-11/50262. 10.1002/app.50262 . hal-03009170

\section{HAL Id: hal-03009170 \\ https://imt-mines-albi.hal.science/hal-03009170}

Submitted on 18 Dec 2020

HAL is a multi-disciplinary open access archive for the deposit and dissemination of scientific research documents, whether they are published or not. The documents may come from teaching and research institutions in France or abroad, or from public or private research centers.
L'archive ouverte pluridisciplinaire HAL, est destinée au dépôt et à la diffusion de documents scientifiques de niveau recherche, publiés ou non, émanant des établissements d'enseignement et de recherche français ou étrangers, des laboratoires publics ou privés. 


\title{
Flexible papers derived from polypyrrole deposited cellulose nanofibers for enhanced electromagnetic interference shielding in gigahertz frequencies
}

\author{
Deepu A. Gopakumar ${ }^{1,6}$ (i) | Avinash R. Pai ${ }^{2}$ | Yasir Beeran Pottathara ${ }^{3}$ | \\ Daniel Pasquini $^{4}$ | Luís Carlos de Morais $^{5}$ | Abdul Khalil H.P.S. ${ }^{1}$ | \\ Ange Nzihou $^{6}$ | Sabu Thomas ${ }^{2}$ \\ ${ }^{1}$ School of Industrial Technology, Universiti Sains Malaysia, Penang, Malaysia \\ ${ }^{2}$ International and Inter University Centre for Nanoscience and Nanotechnology, Mahatma Gandhi University, Kottayam, India \\ ${ }^{3}$ Faculty of Mechanical Engineering, University of Maribor, Maribor, Slovenia \\ ${ }^{4}$ Chemistry Institute, Federal University of Uberlandia-UFU, Uberlândia, Brazil \\ ${ }^{5}$ Universidade Federal do Triângulo Mineiro (UFTM), Uberaba, Brazil \\ ${ }^{6}$ Université de Toulouse, IMT Mines Albi, Albi, France
}

\section{Correspondence}

Deepu A. Gopakumar, Ecole des Mines

d'Albi Carmaux, Centre RAPSODEE-

CNRS UMR 5302, Campus Jarlard-81013

ALBI Cedex 09, Albi 81013, France.

Email: deepu1789@gmail.com

Sabu Thomas, International and Inter University Centre for Nanoscience and Nanotechnology, Mahatma Gandhi University, Kottayam, Kerala 686560, India.

Email: sabuthomas@mgu.ac.in

\section{Funding information}

National Council for Scientific and Technological Development-CNPq, Brazil, Grant/Award Number: 421974/2018-4; Federal University of Uberlandia, Brazil; International and Inter University Centre for Nanoscience and Nanotechnology, Mahatma Gandhi University, India; Université de Toulouse; Visvesvaraya PhD scheme for Electronics and IT, Digital India Corporation, (Formerly Media Lab Asia), MeitY, Government of India, Grant/ Award Numbers: MEITY-PHD-503, PhD MLA/4 (58)/2015-16

\begin{abstract}
An array of highly conductive, lightweight and flexible cellulose nanopapers as effective attenuators of electromagnetic radiations within $8.2-12.4 \mathrm{GHz}$ ( $\mathrm{X}$ band) were formulated via in situ polymerization of pyrrole monomers on to cellulose nanofibers (CNFs). It is quite obvious that the free hydroxyl groups on the surface of CNFs facilitate the formation of intense intermolecular hydrogen bonding with PPy which is envisaged for its excellent electromagnetic shielding performance with an average shielding effectiveness of ca. $22 \mathrm{~dB}$ (>99\% attenuation) at $8.2 \mathrm{GHz}$ for a paper having $1 \mathrm{~mm}$ thickness. The fabricated papers displayed a predominant absorption mechanism (ca. 89\%) rather than reflection (ca. 11\%) for efficiently attenuating electromagnetic radiations, which has a considerable importance in the modern telecommunication sector. Thus, the designed PPy/CNF papers would replace the conventional metal-based shields and pave way for the development of green microwave attenuators functioning via a strong absorption mechanism. The PPy/CNF nanopapers exhibited a DC conductivity of $0.21 \mathrm{~S} / \mathrm{cm}$, a prime requisite for the development of highly efficient electromagnetic shields. Undoubtedly, such nanopapers can be employed in wide range of applications such as electrodes for supercapacitors and other freestanding flexible paper-based devices.
\end{abstract}

\section{KEYWOR D S}

cellulose and other wood products, composites, nanostructured polymers 


\section{1 | INTRODUCTION}

Conducting filler-based polymer composites have been extensively studied for diverse applications such as electronic packing, electromagnetic interference (EMI) shielding, high-storage capacitors, and radar adsorption and so forth. ${ }^{1-6}$ Among these, EMI shielding has gained considerable interest due to the outrageous intermixing of electromagnetic signals emitted from highly sensitive electronic instruments. The repercussion of this electromagnetic pollution not only deteriorate the life of the electronic devices but also poses serious threat to the health of human beings. ${ }^{4,7}$ For practical EMI shielding applications particularly in household appliances, automobiles and aerospace, lightweight flexible polymer composite material has gained a considerable attention for microwave suppression due to its many advantages over the traditionally used metal sheets. ${ }^{8-12}$ Intrinsically conducting polymers (ICPs) are gaining enormous interest as excellent candidates for EMI shielding due to their ease of processing, low cost, lightweight, corrosion resistance, and tuneable conductivities. ${ }^{13-16}$ Moreover, the adsorption dominated shielding mechanism of ICPs suggests as huge potential for EMI shielding applications than metals as shielding mechanism of metals is mainly by reflection of the incident radiation. ${ }^{14,17}$ Among the ICPs, PPy gained considerable attention due to its easy synthesis, environment friendly and high-electrical conductivity. ${ }^{18} \mathrm{PPy}$ has been reported as an efficient material for biomedical field, ${ }^{19} \mathrm{pH}$ sensors, ${ }^{20}$ electrochromic devices, ${ }^{21}$ antistatic materials, ${ }^{22}$ fuel cells,${ }^{23}$ mechanical sensors, ${ }^{24}$ electromagnetic shielding. ${ }^{25,26}$

Nevertheless, the presence of the long order conjugated system in PPy increases the rigidity of the material, which leads in the poor film-forming ability. In addition, the inability of PPy in forming robust films are due to the incapability of PPy to form $\mathrm{H}$ - bonds within the polymer network. In order to rectify this problem, considerable works have been reported on the fabrication of different PPy composites with a wide range of polymeric materials with excellent physical properties and good processability. Various polymeric materials such as polyoxyphenylene, ${ }^{27}$ polyester, ${ }^{28}$ polyamide, ${ }^{29}$ cellulose, ${ }^{26,30,31}$ rubber, ${ }^{24,32}$ and plastic $^{33,34}$ have been extensively studied with PPy for various technological applications. Among them, cellulose nanofibers (CNFs) have drawn more interest due to its abundant, cost effectiveness and eco-friendly nature. Different forms of cellulose such as CNFs, ${ }^{35}$ filter paper, ${ }^{36}$ cellulose nanocrystals, ${ }^{37}$ bacterial nanocellulose,${ }^{26}$ cellulose derivatives, ${ }^{38,39}$ and cellulose aerogels ${ }^{40}$ have been employed as a substrate for the in situ polymerization of PPy. Among the abovementioned cellulose forms, CNFbased papers have been proposed as an efficient substrate for PPy. Since CNF-based nanopapers give adequate $\mathrm{H}$ bonding, the poor film-forming capability and frangibility of PPy could be rectified by fabricating flexible PPy/CNF nanopapers that can be used to shield electromagnetic radiations.

In this context, herein we produced a series of $\mathrm{PPy} / \mathrm{CNF}$ conductive nanopapers via in situ polymerization of polypyrrole on CNFs to suppress the electromagnetic radiations in the $\mathrm{X}$-band frequency. It is also notable that, extensive reports on the $\mathrm{PPy} / \mathrm{CNF}$ conductive nanopapers as effective EMI shielding material for practical device applications are not studied and reported. So far, the only report is by Tang et al., where they fabricated a flexible conductive polypyrrole nanocomposite membranes via in situ chemical synthesis of pyrrole monomer on the surface of the bacterial cellulose and fabricated membrane had an overall shielding effectiveness (SE) of $-15 \mathrm{~dB}$ (around $96.8 \%$ attenuation). The commercial utility of the demonstrated membrane is limited as it requires $-20 \mathrm{~dB}$ for device applications. The key highlight of the demonstrated work is that, the fabricated PPy/CNF conductive nanopapers had accomplished an EMI (SE) of ca. $-22 \mathrm{~dB}$ (more than $99 \%$ of shielding), which makes them as an effective commercial EMI attenuator in the current scenario. In addition, the absorption domination shielding mechanism of the demonstrated PPy/CNF nanopapers facilitates to attenuate the electromagnetic radiations without any threats to the human beings. To the best of our knowledge, the demonstrated work is the first report on $\mathrm{PPy} / \mathrm{CNF}$ conductive nanopapers with an EMI (SE) greater than $-20 \mathrm{~dB}$, which makes the PPy/CNF nanopaper suitable for commercial practical device applications as it surpasses the value of commercial requirement of $-20 \mathrm{~dB}$ via adsorption dominated mechanism.

\section{2 | EXPERIMENTAL}

\section{1 | Materials and instruments}

Pyrrole (pure, $\mathrm{d}=1.022 \mathrm{~g} / \mathrm{ml}, \mathrm{Mw}=93.13 \mathrm{~g} / \mathrm{mol}$ ), ammonium persulfate (APS, $98 \%$ purity, $\mathrm{Mw}=228.20 \mathrm{~g} /$ $\mathrm{mol}$ ), and hydrochloric acid (35\%) were procured from Sigma- Aldrich, Brazil. The CNFs were supplied from SUZANO, Brazil. The CNFs were supplied as in water suspension which were extracted from eucalyptus bleached Kraft pulp and diameters in ranging from 20 to $30 \mathrm{~nm}$. All reagents were used without any further purification.

The DC electrical conductivity of the fabricated $\mathrm{PPy} / \mathrm{CNF}$ nanopapers was measured at the ambient conditions by the standard four-probe method. In order to measure the conductivity of the samples, a Keitheley 
2400 source meter equipped with a gold probe was employed. In order to minimize the error in the DC conductivity value, the measurements were taken in accordance with the van der Pauw method. For highfrequency dielectric measurements of the fabricated PPy/CNF paper, a Novocontrol Alpha High-Resolution Dielectric analyzer with 10 to $15 \mathrm{GHz}$ resonator having the sample dimension of $3 \times 3 \mathrm{~cm}$ was used. In order to investigate the morphology of the $\mathrm{CNF}$ and $\mathrm{PPy} / \mathrm{CNF}$ conductive nanopapers, (CARL ZEISS, EVO MA10) scanning electron microscope (SEM) was used after sputtered with gold coating in an argon atmosphere at $20 \mathrm{~mA}$ for 2 min.

X-ray diffraction (XRD) patterns of the CNF, PPy, and $\mathrm{PPy} / \mathrm{CNF}$ were obtained using SHIMADZU XRD-6000 at a $2 \theta$ range from 5 to $40^{\circ}$. Fourier transform infrared (FTIR) spectra of all samples were recorded on IR prestige-21, FTIR spectrophotometer, Shimadzu in the range of $400-4000 \mathrm{~cm}^{-1}$. The SE of samples was measured by Agilent E8362B (10 MHz-20 GHz) two-port PNA Network analyzer attached to a Keycom waveguide to evaluate the scattering parameters at the frequency range of $8.2-12.4 \mathrm{GHz}$ (X band). The $\mathrm{SE}$ of the samples were calculated from the scattering parameters (S11, S12, S22, and S21) using standard equations.

\section{2 | Preparation of $\mathrm{PPy} / \mathrm{CNF}$ suspensions (in situ polymerization)}

In order to synthesize polypyrrole, in situ polymerization strategy was used in this current study. For the preparation of in situ polymerized PPy/CNF suspension with various ratios of $0.2: 1,0.3: 1,0.5: 1,0.8: 1,0.9: 1$, and 1:1, various amounts of pyrrole monomer were dissolved in $40 \mathrm{~g}$ of CNF suspension $(1.15 \mathrm{mg} / \mathrm{ml})$ at ambient temperature for $1 \mathrm{~h}$. After this, the prepared suspension was cooled at $1^{\circ} \mathrm{C}$, subsequently APS solution (dissolved in
$40 \mathrm{ml}$ of $1 \mathrm{M} \mathrm{HCl}$ ) was added drop wisely into the cooled suspension. After $2 \mathrm{~h}$, the black suspensions of PPy/CNF were formed and suspended. Afterwards, the resultant suspensions were filtered and washed with distilled water and acetone in order to remove the oxidized components and unreacted pyrrole monomer.

\section{3 | Fabrication of $\mathrm{PPy} / \mathrm{CNF}$ flexible nanopapers}

The resultant suspensions were vacuum filtrated via filtration assembly with a cellulose ester membrane with $0.45 \mu \mathrm{m}$ pore size and diameter of $47 \mathrm{~mm}$ to fabricate $\mathrm{PPy} / \mathrm{CNF}$ nano flexible paper. Finally, the fabricated nanopaper was washed with $1 \mathrm{M} \mathrm{HCl}$ in order to remove all impurities followed by drying at $70^{\circ} \mathrm{C}$ for $4 \mathrm{~min}$ in hot press.

\section{3 | RESULTS AND DISCUSSION}

The scheme in Figure 1 represents the formation of $\mathrm{PPy} / \mathrm{CNF}$ flexible composite paper through the in situ polymerization of pyrrole on the CNFs. As demonstrated, the polypyrrole could be coated on CNF surface as shown in Figure 2 via hydrogen bonding between the nitrogen of PPy and hydroxyl group of CNFs as shown in Figure 3. Upon addition of the APS oxidant, the pyrrole monomers would be polymerized on the surface of these CNF fibers, which resulted in the formation of dark black color flexible paper.

\section{$3.1 \quad$ FTIR studies}

FTIR absorption spectrum of PPy powder, PPy/CNF, and $\mathrm{CNF}$ nanopapers are given in Figure 4. From the
F I G U RE 1 Pictorial representation showing the fabrication of $\mathrm{PPy} / \mathrm{CNF}$ nanopaper via in situ polymerization of pyrrole monomers on cellulose nanofibers (CNFs) [Color figure can be viewed at wileyonlinelibrary.com]
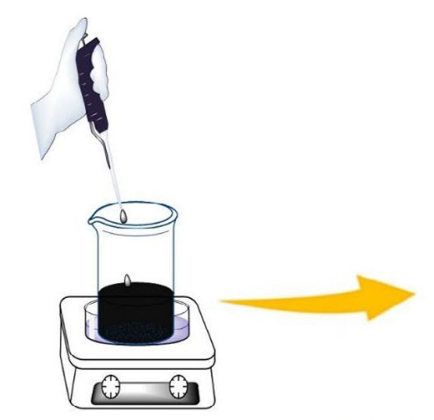

In-situ polymerization of Pyrrole with CNF suspension
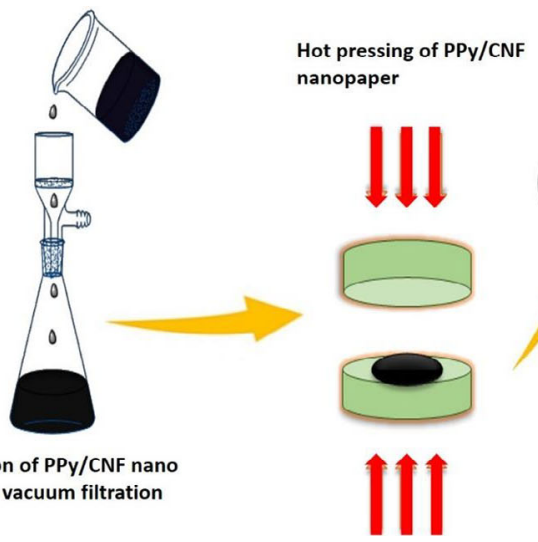

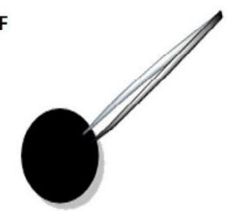

Fabrication of PPy/CNF nano paper via vacuum filtration 

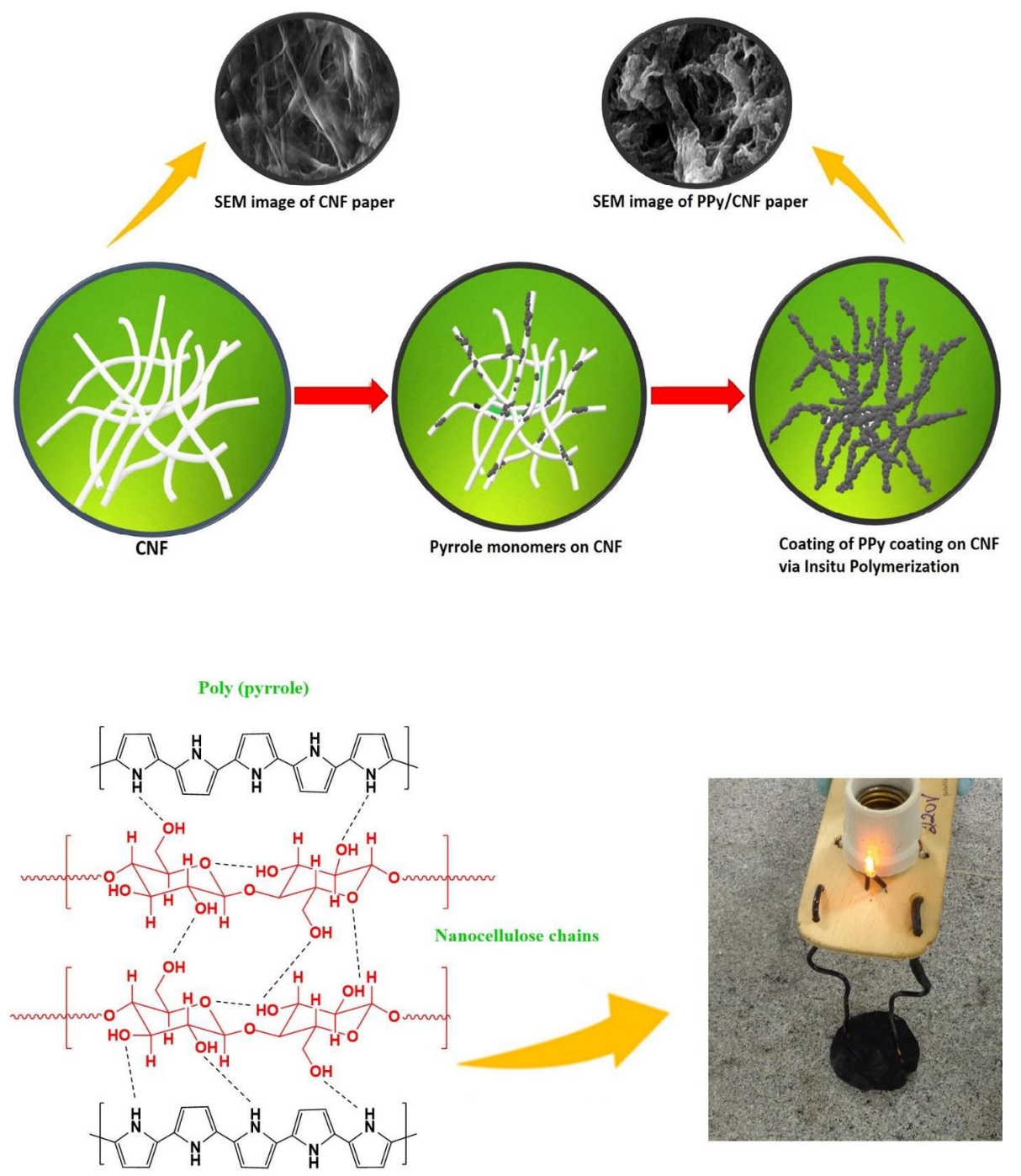

FIG URE 2 Schematic

representation for in situ polymerization of pyrrole onto CNF. CNF, cellulose nanofiber [Color figure can be viewed at wileyonlinelibrary.com]
F I G URE 3 Secondary interactions between CNF and PPy and digital photo of PPy/CNF paper. CNF, cellulose nanofiber [Color figure can be viewed at wileyonlinelibrary.com]

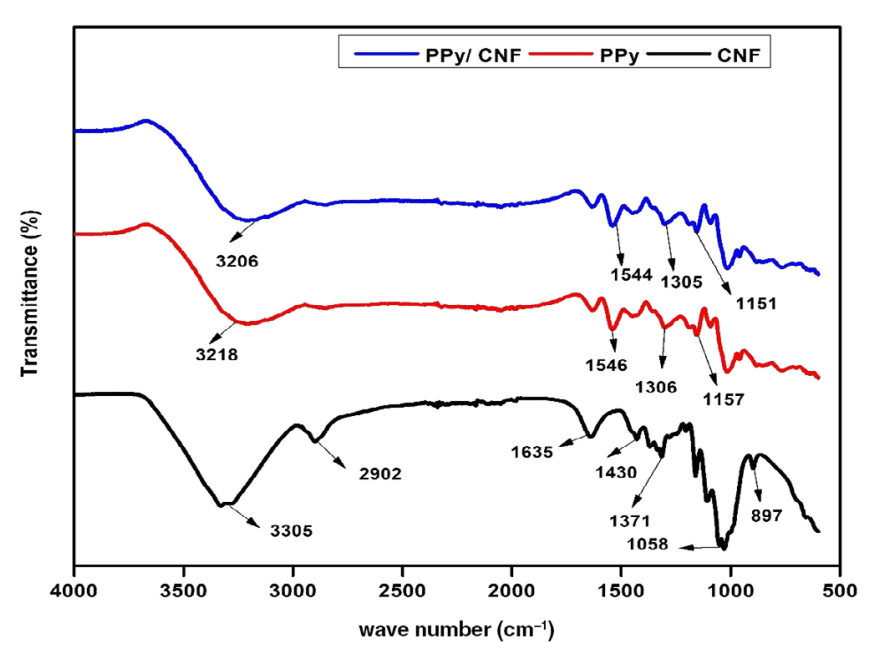

F I G U RE 4 FTIR spectra of PPy/CNF and CNF flexible papers. CNF, cellulose nanofiber; FTIR, Fourier transform infrared [Color figure can be viewed at wileyonlinelibrary.com]
Figure 4, neat CNF exhibited the absorption peak at $3305,2902,1430,1371,1058$, and $897 \mathrm{~cm}^{-1}$, which was due to the $-\mathrm{OH}$ stretching, $-\mathrm{CH}$ stretching, $-\mathrm{CH}_{2}$ and $-\mathrm{OCH}$ in-plane bending, $-\mathrm{CH}$ bending, $\mathrm{C}-\mathrm{O}-\mathrm{C}$ stretching, respectively. ${ }^{41,42}$ In the case of PPy, strong bands arising at 3218 and $1546 \mathrm{~cm}^{-1}$ was attributed to the $\mathrm{N}-\mathrm{H}$ stretching vibration and $\mathrm{C}=\mathrm{C}$ stretching of aromatic ring of PPy. Moreover, the peaks at 1306 and $1151 \mathrm{~cm}^{-1}$ corresponds to $\mathrm{C}-\mathrm{H}$ in-plane ring bending and $\mathrm{C}-\mathrm{N}$ in-plane ring deformation respectively. ${ }^{43}$ In the case of PPy/CNF nanopaper, a superposition of the characteristic peaks of both CNF and PPy was observed without any formation of new peaks. This infers that, there was no chemical reaction between both CNF and PPy. It is worth mentioning that the major peaks of PPy (3218, 1546, and $1157 \mathrm{~cm}^{-1}$ ) was shifted to lower wave numbers in PPy/CNF nanopapers (3206, 1544, and $1151 \mathrm{~cm}^{-1}$ ) which is ascribed to the strong 


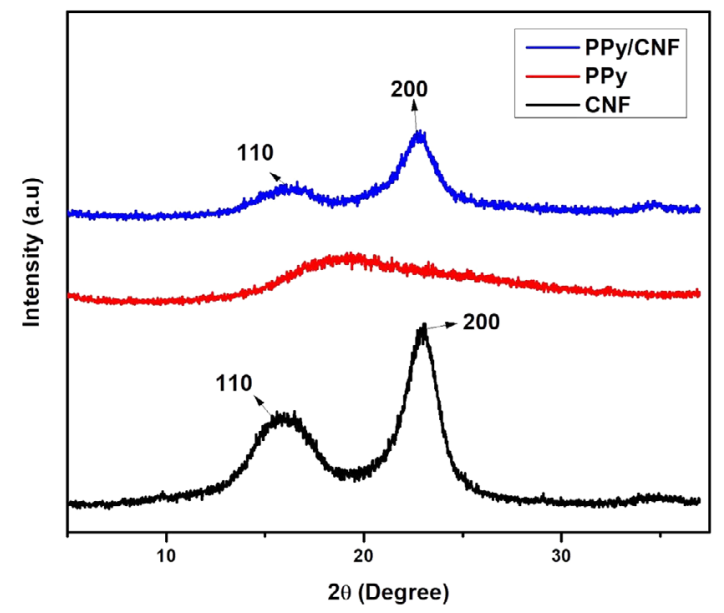

FI G U RE 5 XRD profiles of PPy powder, PPy/CNF and CNF nanopapers. CNF, cellulose nanofiber; XRD, X-ray diffraction [Color figure can be viewed at wileyonlinelibrary.com]

intermolecular hydrogen bonding interaction between $\mathrm{CNF}$ and PPy. ${ }^{44-46}$

\section{2 | Crystallinity studies}

The XRD profiles of PPy powder, $\mathrm{PPy} / \mathrm{CNF}$ and CNF nanopapers are shown in Figure 5. The neat CNF paper exhibited two diffraction peaks at $2 \theta=16.3^{\circ}$ and $2 \theta=22.6^{\circ}$, assigned to (110) and (200) planes. The XRD pattern of cellulose type I structure was clearly reflected in the neat CNF paper. ${ }^{42}$ The pure PPy exhibited a broad diffraction peak around $19.6^{\circ}$, shows its amorphous nature $^{47,48}$ The XRD spectra of PPy/CNF nanopaper shows the combination of PPy and CNF diffraction profiles. Comparing with the neat CNF paper, the intensity of the diffraction peaks was reduced in the $\mathrm{PPy} / \mathrm{CNF}$ nanopaper, which confirms the uniform coating of pyrrole monomers on to the surface of CNFs during the in situ polymerization reaction.

\section{3 | Surface topography and cross section of PPy/CNF flexible nanopapers}

To investigate the surface topography of the fabricated PPy/CNF nanopaper SEM images was used. From the Figure 6(a), it could be seen that each CNF was merged together to form a bundle of fibers during vacuum filtration via strong intermolecular hydrogen bonding within the CNFs. Hence, it becomes practically difficult to distinguish individual CNF fibers alone from Figure 6(a). By comparing the Figure 6(a),(b), it could be clearly seen that pyrrole monomers were uniformly coated over the

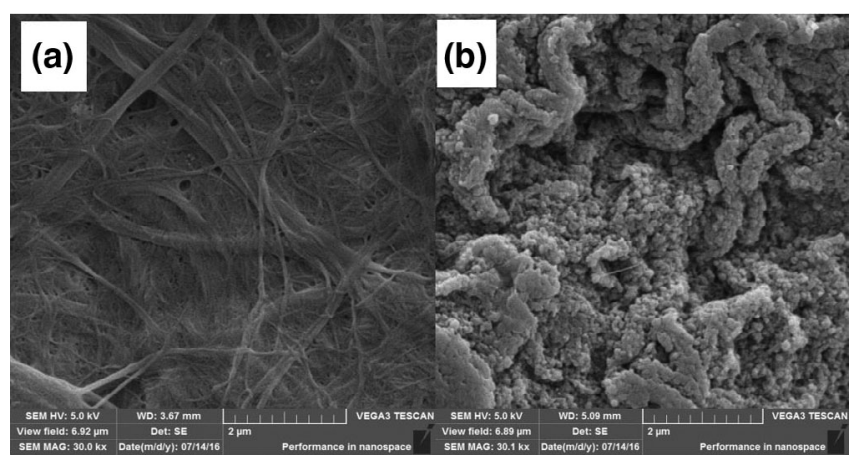

F I G U RE 6 SEM micrographs of (a) CNF paper and (b) PPy/ CNF paper. CNF, cellulose nanofiber; SEM, scanning electron microscope

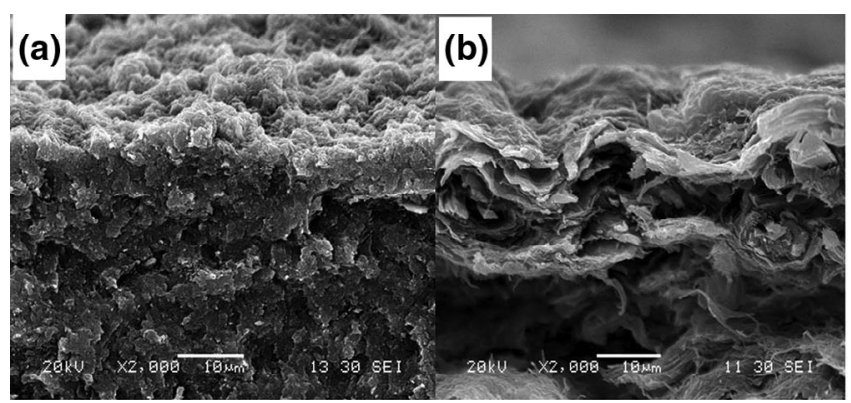

FI G URE 7 SEM micrographs of the cross-section of (a) PPy/ $\mathrm{CNF}$ and (b) CNF paper. CNF, cellulose nanofiber; SEM, scanning electron microscope

CNFs through in situ polymerization, and thereby resulted in the highly conductive $\mathrm{PPy} / \mathrm{CNF}$ nanopapers. Even though, both neat $\mathrm{CNF}$ paper and $\mathrm{PPy} / \mathrm{CNF}$ nanopaper exhibited similar morphology, surface roughness and diameter of CNFs was enhanced due to the uniform coating of pyrrole monomer on the surface of $\mathrm{CNF}$ in $\mathrm{PPy} / \mathrm{CNF}$ nanopaper.

From the Figure 6(b), it was shown that the fibers were merged together which implies that, the strong hydrogen bonding interaction between nitrogen of PPy and $\mathrm{OH}$ group of CNFs, which was confirmed from the FTIR studies. The cross-sectional view of the neat CNF and PPy/CNF nanopaper were illustrated in Figure 7(a), (b) respectively. The cross-section of the neat CNF exhibited a layered pattern, which was attributed to the strong H-bonding among the CNFs itself. The crosssection of the both papers exhibited a similar layer pattern structure but $\mathrm{PPy} / \mathrm{CNF}$ nanopaper shows some white spots illustrating the broken ends of the CNFs (see Figure 7(a)), which clearly signifying a good bonding between CNFs and PPy. 


\section{4 | Conductivity studies of the fabricated $\mathrm{PPy} / \mathrm{CNF}$ paper}

For the transport of mobile charge carriers, it is essential to have a continuous network of PPy on the surface of CNFs even at low concentration of PPy $(0.2: 1){ }^{49,50}$ Table 1 illustrates the conductivity values of $\mathrm{PPy} / \mathrm{CNF}$ nanopapers with different concentrations of PPy. The high aspect ratio of CNFs and the strong hydrogen bonding between the PPy and CNF had resulted in the highly conducting nature of PPy/CNF nanopapers. It is noteworthy that, the fabricated PPy/CNF nanopapers with ratio of 1:1 (PPy/CNF) showed a highest value of $0.21 \mathrm{~S} / \mathrm{cm}$. Figure 8(a) illustrates the image of the flexible $\mathrm{PPy} / \mathrm{CNF}$ nanopaper, and Figure 8(b) shows the conductivity of the fabricated PPy/CNF (1:1) nanopaper (see Video S1).

\section{5 | Dielectric properties of $\mathrm{PPy} / \mathrm{CNF}$ nanopapers}

If a material exhibits decent dielectric properties with high dielectric permittivity and dielectric loss factor, the material would display higher EMI (SE). ${ }^{51}$ In order to verify the dielectric properties of nanopapers at $\mathrm{X}$ band,

T A B L E 1 Conductivity values of PPy/CNF nanopapers with different PPy ratios

\begin{tabular}{|l|l|}
\hline CNF/PPy ratios & $\begin{array}{l}\text { DC conductivity } \\
\text { (S/cm) }\end{array}$ \\
\hline $1: 1.0$ & 0.21 \\
\hline $1: 0.9$ & 0.02 \\
\hline $1: 0.8$ & 0.0089 \\
$1: 0.5$ & 0.006 \\
\hline $1: 0.3$ & 0.0033 \\
\hline $1: 0.2$ & 0.00012 \\
\hline
\end{tabular}

Abbreviation: CNF, cellulose nanofiber.
PPy/ CNF (1:1) nanopaper was studied at a frequency of 10 and $15 \mathrm{GHz}$. The variation of dielectric constant $\left(\varepsilon^{1}\right)$ and dielectric loss $\left(\varepsilon^{11}\right)$ properties of PPy: CNF (1:1) composite paper at a frequency of 10 and $15 \mathrm{GHz}$ is shown in Figure 9. At a frequency of $10 \mathrm{GHz}$, the nanopaper exhibited the dielectric properties of $\varepsilon^{1}=2.93$ and $\varepsilon^{11}=0.96$, whereas the dielectric values decreased as $\varepsilon^{1}=2.15$ and $\varepsilon^{11}=0.93$ at a frequency of $15 \mathrm{GHz}$. According to Maxwell-Wagner-Sillars (MWS) theory, $\varepsilon^{1}$ originates due to the matrix-filler mismatch at the interface of a polymer composites which outcomes the interfacial polarization. The decrease of $\varepsilon^{1}$ with increase in frequency for PPy/CNF nanopaper would be attributed to the charge dissipation at the matrix-filler interface. ${ }^{52}$ That means, at higher frequencies such as $15 \mathrm{GHz}$, the dipoles might attain the ability to violate the filed disparities and thus the charge accumulation will be lower. The excellent dielectric performance of PPy-CNF nanopaper in the high-frequency region makes it as a suitable candidate for electromagnetic shielding in the $\mathrm{X}$-band region.

\section{6 | Electromagnetic attenuation performance of fabricated $\mathrm{PPy} / \mathrm{CNF}$ nanopapers}

The electromagnetic screening ability of the fabricated $\mathrm{PPy} / \mathrm{CNF}$ nanopapers was analyzed by recording the scattering parameters using a vector network analyzer (VNA) with an $\mathrm{X}$ band (8.2-12.4 GHz) waveguide. The SE value is usually expressed in terms of decibels $(\mathrm{dB})$ which is the logarithmic ratio of the incident EM power to the transmitted EM power. The main criterion for achieving higher EMI SE value is to enhance the electrical conductivity of the system. ${ }^{53}$ The formation of a well-defined coating of polypyrrole onto CNFs resulted in a higher DC electrical conductivity of $0.21 \mathrm{~S} / \mathrm{m}$ for $1: 1 \mathrm{PPy} / \mathrm{CNF}$ nanopapers. As per the existing EMI shielding theories, total SE (SE Total) value of any EMI shield is the summation of three shielding components viz shielding by

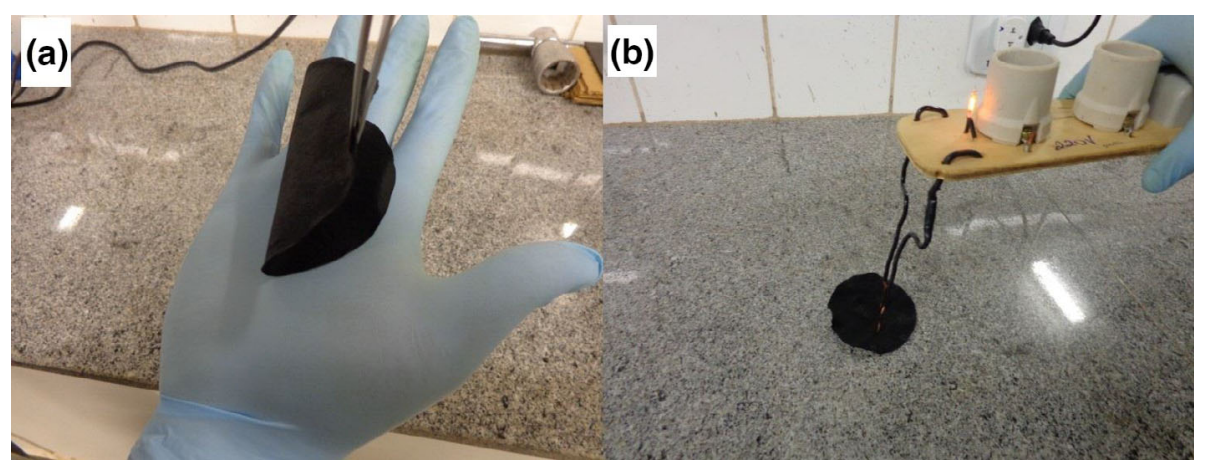

F I G URE 8 Digital images of

(a) fabricated $\mathrm{PPy} / \mathrm{CNF}$ paper

(b) conductivity demonstration of PPy/CNF paper. CNF, cellulose nanofiber [Color figure can be viewed at wileyonlinelibrary.com] 
absorption $\left(\mathrm{SE}_{\mathrm{A}}\right)$, shielding by reflection $\left(\mathrm{SE}_{\mathrm{R}}\right)$, and shielding due to multiple internal reflections ( $\left.\mathrm{SE}_{\mathrm{MR}}\right)$

$$
\mathrm{SE}_{\mathrm{Total}}(\mathrm{dB})=\mathrm{SE}_{\mathrm{A}}+\mathrm{SE}_{\mathrm{R}}+\mathrm{SE}_{\mathrm{MR}} \text {. }
$$

Usually, when $\mathrm{SE}_{\mathrm{A}}$ component is higher than $10 \mathrm{~dB}$, the $\mathrm{SE}_{\mathrm{MR}}$ value can be neglected and $\mathrm{SE}_{\mathrm{Total}}$ is the summation of only $\mathrm{SE}_{\mathrm{A}} \& \mathrm{SE}_{\mathrm{R}}$.

The shielding effectivenees $\mathrm{SE}_{\text {Total }}, \mathrm{SE}_{\mathrm{A}}$ and $\mathrm{SE}_{\mathrm{R}}$ can be re-expressed in terms of scattering parameters as given below.

$$
\begin{gathered}
\mathrm{SE}_{\text {Total }}(\mathrm{dB})=10 \log \frac{1}{\left|S_{21}\right|^{2}}=10 \log \frac{1}{\left|S_{12}\right|^{2}}, \\
\mathrm{SE}_{\mathrm{A}}(\mathrm{dB})=10 \log _{10}\left[\frac{\left(1-S_{11}\right)^{2}}{S_{12}{ }^{2}}\right],
\end{gathered}
$$

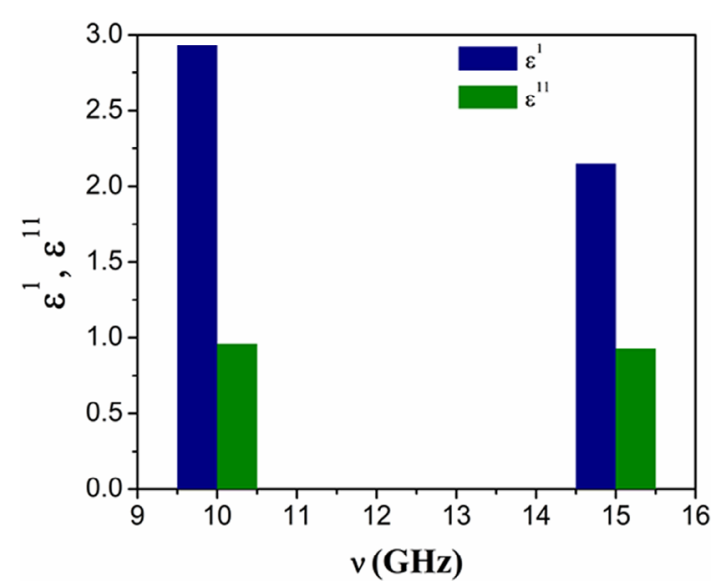

F I G U R E 9 Variation of dielectric constant $\left(\varepsilon^{1}\right)$ and dielectric loss $\left(\varepsilon^{11}\right)$ of PPy:CNF (1:1) flexible nanopaper as a function of frequency at 10 and $15 \mathrm{GHz}$. CNF, cellulose nanofiber [Color figure can be viewed at wileyonlinelibrary.com]

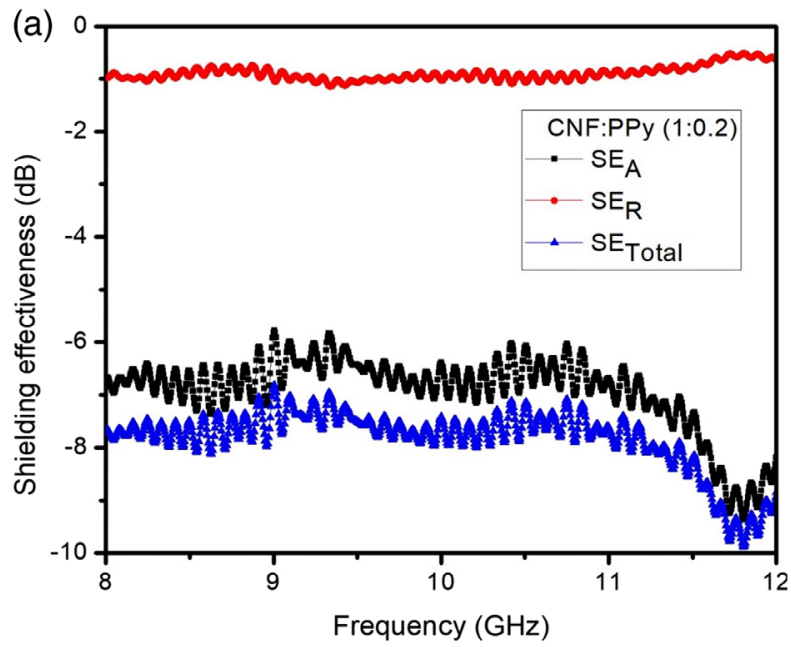

$$
\mathrm{SE}_{\mathrm{R}}(\mathrm{dB})=10 \log _{10}\left[\frac{1}{\left(1-S_{11}\right)^{2}}\right] \text {, }
$$

Where, $S_{11}, S_{21}$, and $S_{12}$ are the scattering parameters could be traced from the VNA.

In the present study, $1 \mathrm{~mm}$ thick $\mathrm{PPy} / \mathrm{CNF}$ nanopapers were used for all EMI shielding analysis as it was found to be optimum thickness from our previous work on Polyaniline (PANI)/CNF nanopapers. ${ }^{42}$ Figure 10 shows the variation of EMI SE values of 1:0.2 and 1:0.5 PPy/CNF nanopapers with a maximum of ca. $8 \mathrm{~dB}$ and ca. $-14 \mathrm{~dB}$ respectively at $8.2 \mathrm{GHz}$ in $\mathrm{X}$-band region with $1 \mathrm{~mm}$ paper thickness. However, as the concentration of PPy was further increased, it resulted in a higher EMI SE value of ca. $-22 \mathrm{~dB}$ (>99\% shielding) in Xband region as seen from Figure 11(a). This can be attributed to the higher electrical conductivity of the 1:1 $\mathrm{PPy} / \mathrm{CNF}$ nanopapers, which has resulted in a higher EMI SE value. It is also noteworthy that all the PPy/CNF nanopapers suppressed the incoming electromagnetic radiations via a dominant absorption mechanism (ca. 89\%) and minimal shielding by reflection (ca. 11\%) (see Figure 11(b). The formation of strong intra molecular hydrogen bonding between the nitrogen of the polypyrrole and the hydroxyl groups of CNFs resulted in a uniform coating of polypyrrole on CNFs. These secondary forces are attributed to the strong affinity of polypyrrole on CNFs surface and thereby enhancing the EMI shielding ability of PPy/CNF nanopapers. These attributes make PPy/CNF nanopapers as a platform for developing and designing green EMI shielding materials for various end applications in radar and terrestrial communication systems.

For any EMI shielding material for practical device applications, a minimum EMI SE value of $-20 \mathrm{~dB}$ is

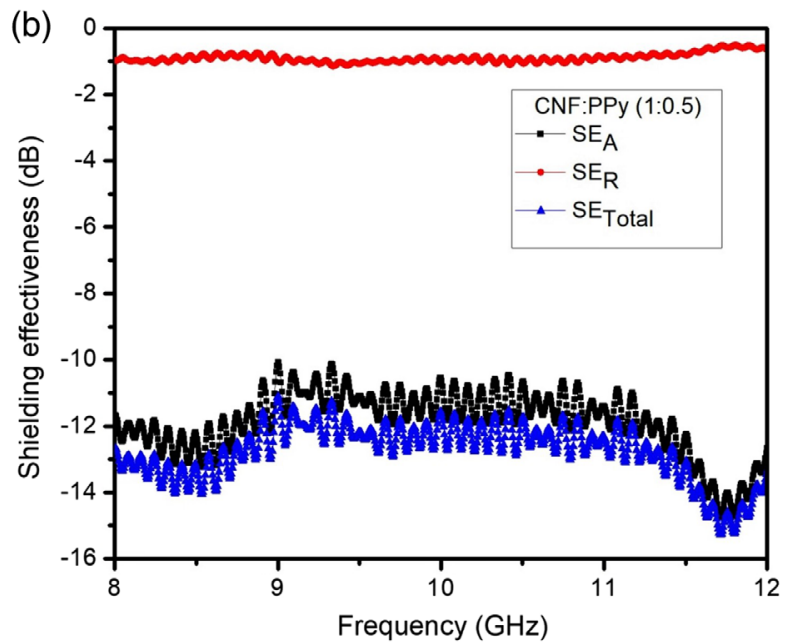

F I G U R E 10 EMI shielding effectiveness of the (a) (1:0.2) and (b) (1:0.5) PPy/CNF flexible paper at 1 mm thickness in the X band (8.2-12 GHz). CNF, cellulose nanofiber; EMI, electromagnetic interference [Color figure can be viewed at wileyonlinelibrary.com] 

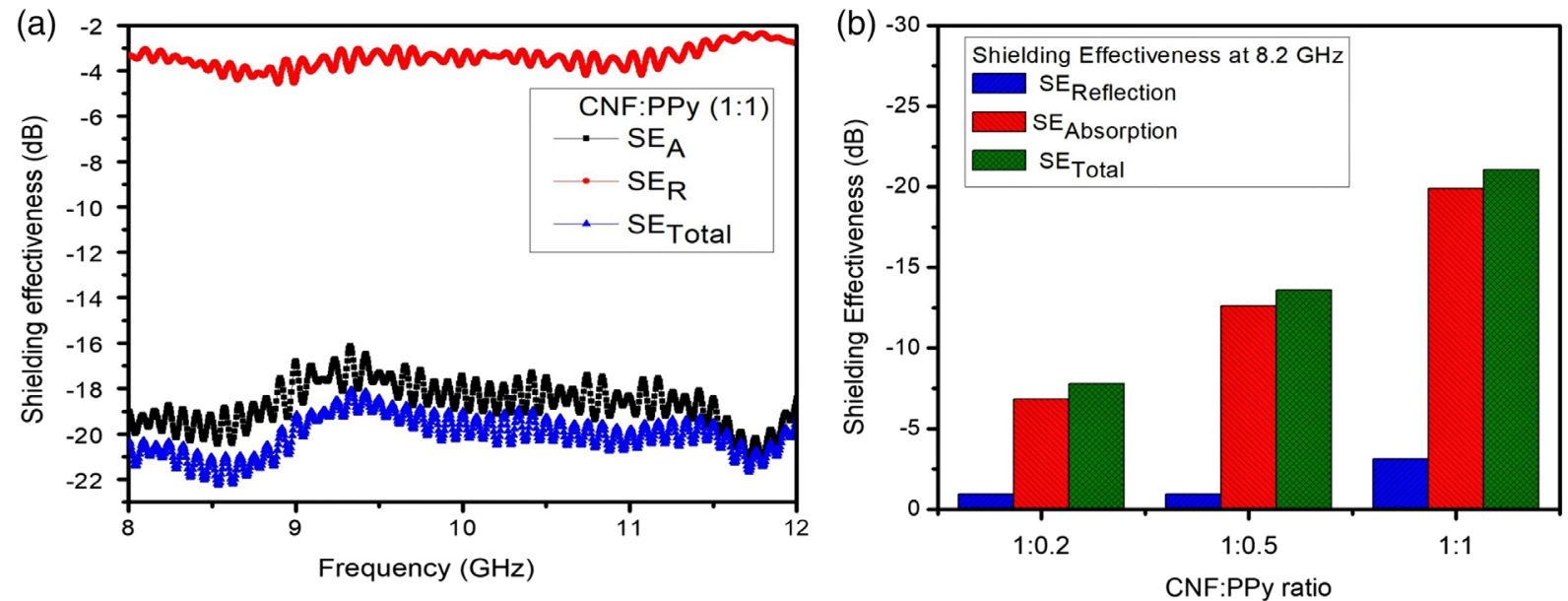

F I G U RE 11 EMI shielding effectiveness of the (1:1) PPy/CNF flexible paper at $1 \mathrm{~mm}$ thickness in the X band (8.2-12 GHz). CNF, cellulose nanofiber; EMI, electromagnetic interference [Color figure can be viewed at wileyonlinelibrary.com]

T A B L E 2 Comparison of shielding effectiveness of various cellulose-based nanocomposites

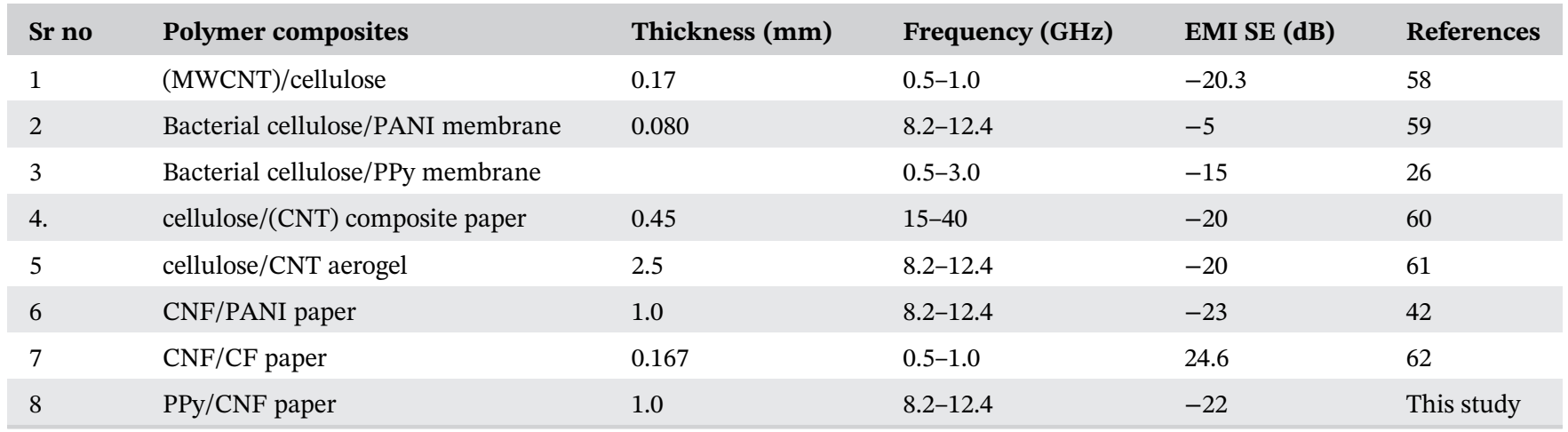

Abbreviations: CNF, cellulose nanofiber; CNT, carbon nanotube; EMI, electromagnetic interference; MWCNT, Multi-walled carbon nanotube.

considered suitable for the smooth functioning of the electronic device. ${ }^{54,55}$ However, there are only limited reports on PPy/CNF based nanopapers as efficient microwave absorbers. Recently, L. Tang et al. (2015) fabricated flexible and highly conductive membranes via in situ polymerization of pyrrole monomer onto bacterial cellulose membranes. ${ }^{56}$ These membranes exhibited a maximum EMI SE value of only $-15 \mathrm{~dB}$ in the region of 500-3000 MHz. But, in this study, we enhanced the EMI (SE) value of $\mathrm{PPy} / \mathrm{CNF}$ nanopapers to ca. $-22 \mathrm{~dB}$ in $\mathrm{X}$ band $(8.2-12.4 \mathrm{GHz})$ region which enables them applicable for commercial device applications. Table 2 lists out some of the existing works reported on EMI Shielding materials based on cellulose and one can infer that achieving an EMI (SE) value of $\geq 20 \mathrm{~dB}$ in cellulosic materials is a notable value so as to make these green EMI shields commercially viable.

In order to study the application of these nanopapers for EMI shielding application, the 1:1 PPy/CNF nanopapers were tested using an RF detector circuit and mobile phone. It was found that the RF detector could easily detect excess radiations emitted out from mobile phones when placed in close proximity to the device. A red led gives an indication of the excess radiation emitted as shown in Figure 12(a). When we place 1:1 PPy/CNF nanopapers in between the mobile phone and the device (see Figure 12(b)), the led does not glow which infers that the excess radiations are being absorbed by the fabricated nanopapers (see Video S2). The prime shielding mechanism of PPy/CNF nanopapers is via strong absorption of the incoming electromagnetic radiations and Figure 13 shows a cartoon for possible shielding mechanism of the fabricated nanopapers.

\section{7 | Evaluation of skin depth}

The vital thickness at which the intensity of the incident EM wave reduces to 1/e or $37 \%$ of its initial intensity is termed as skin depth of an electromagnetic shield. The skin effect is very much correlated with the shielding ability and it is desired to have a minimum skin depth for 


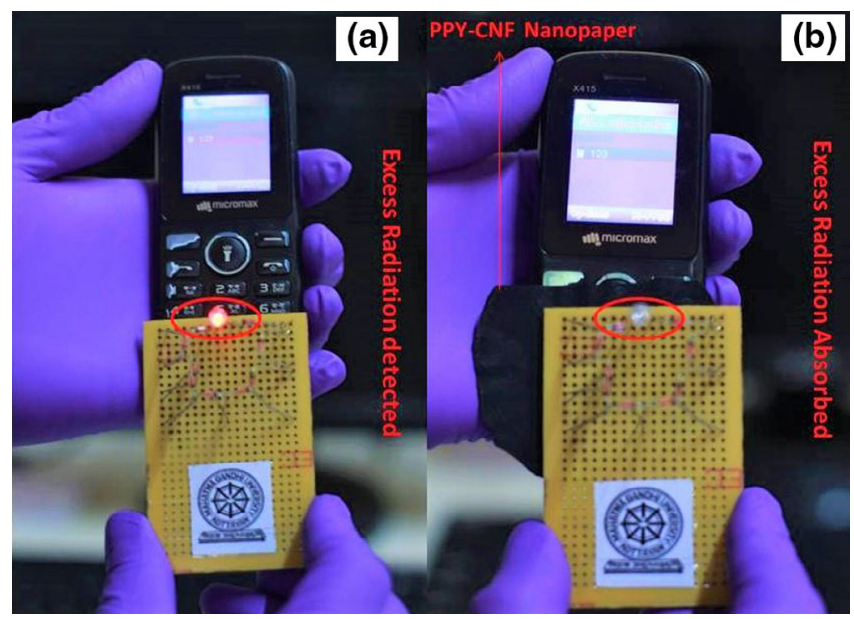

FI G URE 12 (a) Excess radiation emitted from mobile phone detected using a RF detector circuit. (b) PPy/CNF (1:1) nanopapers absorbing the excess radiation from the mobile phone. CNF, cellulose nanofiber [Color figure can be viewed at wileyonlinelibrary.com]

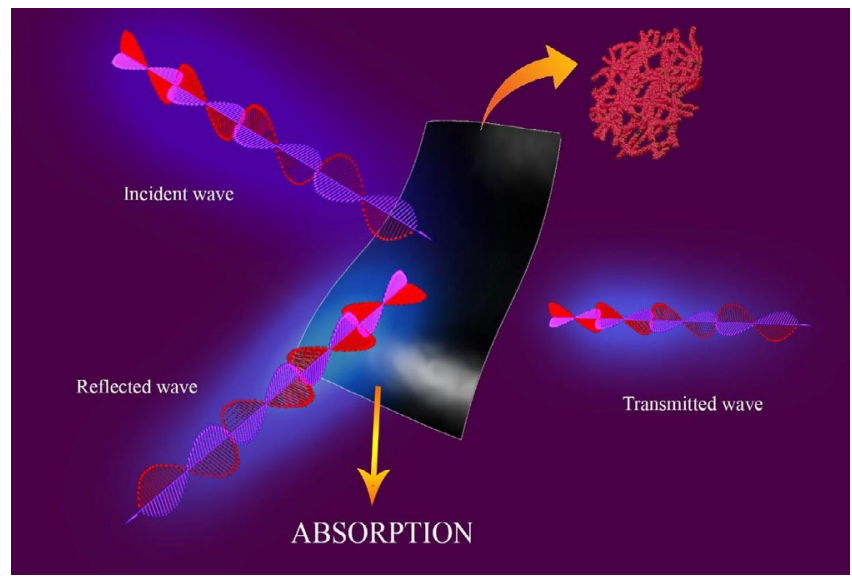

F I G U RE 13 Pictorial representation of EMI shielding mechanism of fabricated PPy/CNF flexible paper. CNF, cellulose nanofiber; EMI, electromagnetic interference [Color figure can be viewed at wileyonlinelibrary.com]

enhanced performance of the shields. ${ }^{57}$ It can be expressed as given below.

$$
\operatorname{Skin} \operatorname{Depth}(\delta)=\frac{1}{\sqrt{\pi f \mu \sigma}}=-8.68 \frac{t}{\mathrm{SE}_{\mathrm{A}}}
$$

From the above equation, it can be observed that skin depth is inversely proportional to electrical conductivity. Hence, in the present study, PPy/CNF nanopapers with low electrical conductivity exhibited higher skin depth and vice versa. Nevertheless, all PPy/CNF nanopapers

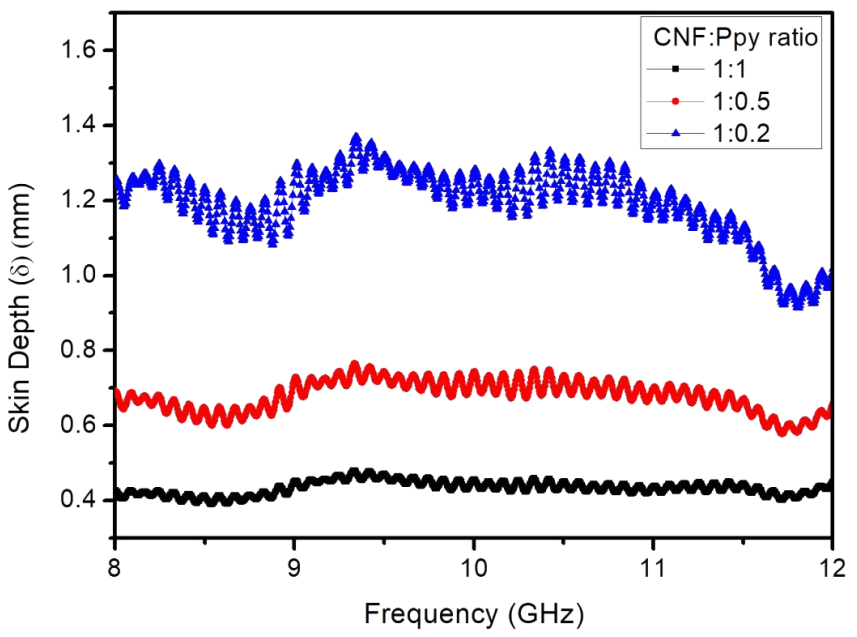

F I G URE 14 The skin depth v/s frequency plot for 1:0.2, 1:0.5, and 1:1 CNF:PPy nanopapers in the $\mathrm{X}$ band. CNF, cellulose nanofiber [Color figure can be viewed at wileyonlinelibrary.com]

exhibited an effective attenuation by an absorption dominant mechanism, which will significantly reduce the skin depth of the nanopapers. The variation of skin depth of 1:1, 1:0.5 \& 1:0.2 CNF:PPy nanopapers is shown in Figure 14, and was found to $0.41,0.6$, and $1.24 \mathrm{~mm}$, respectively.

\section{4 | CONCLUSION}

The present study reports a facile approach for the fabrication of highly processable $\mathrm{PPy} / \mathrm{CNF}$ suspensions containing various pyrrole ratios. The $\mathrm{PPy} / \mathrm{CNF}$ flexible composite papers from an equimolar proportion of PPy/CNF exhibited a high-DC conductivity value of $0.21 \mathrm{~S} / \mathrm{cm}$. SEM images and FTIR studies revealed that a continuous network of PPy was formed on the surface of the CNFs as a result of the secondary interaction via hydrogen bonding between the former and the latter and is of substantial importance for attenuating the EM waves. The proposed composite nanopapers demonstrated a predominant absorption mechanism (ca. 89\%) which was superior to reflection mechanism (ca. 11\%) and were found to have a SE of ca. $-22 \mathrm{~dB}$ for a $1.0 \mathrm{~mm}$ thick paper at $8.2 \mathrm{GHz}$. Also, these flexible nanopapers made by simple and easily scalable process are ideal for a good deal of applications such as flexible electrodes, sensors, and electrically conductive and flexible films and other flexible paper-based devices. Moreover, results from the EMI shielding measurements also confirmed that the $\mathrm{PPy} / \mathrm{CNF}$ flexible composite paper is an excellent candidate for attenuating electromagnetic radiations. We envision that this study will open up a new platform for 
developing green microwave attenuators for future highend applications.

\section{ACKNOWLEDGMENT}

Deepu A. Gopakumar is grateful to IMT Mines Albi, RAPSODEE CNRS, for providing Post-Doctoral fellowship. Avinash R. Pai would like to acknowledge the financial support received from Visvesvaraya $\mathrm{PhD}$ scheme for Electronics and IT, Digital India Corporation, (Formerly Media Lab Asia), MeitY, Government of India (Ref No: PhD MLA/4 (58)/2015-16, Unique Awardee No: MEITY-PHD-503). The authors gratefully acknowledge support from Université de Toulouse, IMT Mines Albi, RAPSODEE CNRS UMR, France, International and Inter University Centre for Nanoscience and Nanotechnology, Mahatma Gandhi University, India and Federal University of Uberlandia, Brazil. Also, Thanks to National Council for Scientific and Technological DevelopmentCNPq, Brazil (Process 421974/2018-4).

\section{ORCID}

Deepu A. Gopakumar (10 https://orcid.org/0000-00019394-6302

\section{REFERENCES}

[1] D. D. Chung, Carbon N. Y. 2001, 2, 279.

[2] L. Ci, J. Suhr, V. Pushparaj, X. Zhang, P. M. Ajayan, Nano Lett. 2008, 9, 2762.

[3] D. M. Bigg, D. E. Stutz, Polym. Compos. 1983, 1, 40.

[4] P. Theilmann, D. J. Yun, P. Asbeck, S. H. Park, Org. Electron. physics, Mater. Appl. 2013, 6, 1531.

[5] Z. Liu, G. Bai, Y. Huang, F. Li, Y. Ma, T. Guo, X. He, X. Lin, H. Gao, Y. Chen, J. Phys. Chem. C 2007, 37, 13696.

[6] M. Hoefer, P. R. Bandaru, Appl. Phys. Lett. 2009, 18, 183108.

[7] J. Ma, M. Zhan, K. Wang, ACS Appl. Mater. Interfaces 2015, $1,563$.

[8] S. Maiti, N. K. Shrivastava, S. Suin, B. B. Khatua, ACS Appl. Mater. Interfaces 2013, 5, 4712.

[9] A. Fletcher, M. C. Gupta, K. L. Dudley, E. Vedeler, Compos. Sci. Technol. 2010, 70, 953.

[10] M. Arjmand, A. A. Moud, Y. Li, U. Sundararaj, RSC Adv. 2015, $70,56590$.

[11] Y. Zhang, Z. Wang, B. Zhang, G.-L. Zhao, S. M. G., RSC Adv. 2015, 5, 93499.

[12] M. H. Al-Saleh, U. Sundararaj, Carbon N. Y. 2009, 47, 1738.

[13] C. Yang, H. Wei, L. Guan, J. Guo, Y. Wang, X. Yan, X. Zhang, S. Wei, Z. Guo, J. Mater. Chem. A 2015, 29, 14929.

[14] P. Saini, M. Aror, New Polymers for Special Applications 2012, $3,73$.

[15] Y. Bhattacharjee, I. Arief, S. Bose, J. Mater. Chem. C 2017, 5, 7390.

[16] S. Sankaran, K. Deshmukh, M. B. Ahamed, S. K. Khadheer Pasha, Compos. Part A Appl. Sci. Manuf. Manuf. 2018, 114, 49.

[17] P. Chandrasekhar, K. Naishadham, Synth. Met. 1999, 105, 115.

[18] M. Omastová, M. Mičušík, Chem. Pap. 2012, 5, 392.
[19] J. G. Hardy, J. Y. Lee, C. E. Schmidt, Curr. Opin. Biotechnol. 2013, 24, 847.

[20] J. J. Miasik, A. Hooper, B. C. Tofield, J. Chem. Soc. Faraday Trans. 1 Phys. Chem. Condens. Phases 1986, 4, 1117.

[21] S. Takagi, S. Makuta, A. Veamatahau, Y. Otsuka, Y. Tachibana, J. Mater. Chem. 2012, 22, 22181.

[22] A. Varesano, C. Tonin, Text. Res. J. 2008, 8, 2465.

[23] X. Yuan, X. L. Ding, C. Y. Wang, Z. F. Ma, Energy Environ. Sci. 2013, 6, 1105.

[24] A. P. Tjahyono, K. C. Aw, J. Travas-Sejdic, Sensors Actuators, B Chem. 2012, 166, 426.

[25] A. I. Kaur, S. K. Dhawan, Synth. Met. 2012, 162, 1471.

[26] L. Tang, J. Han, Z. Jiang, S. Chen, H. Wang, Carbohydr. Polym. 2015, 117, 230.

[27] J. Aguilar-Hernandez, J. Skarda, K. Potje-Kamloth, Synth. Met. 1998, 95, 197.

[28] Z. Yildiz, I. Usta, A. Gungor, Text. Res. J. 2012, 20, 2137.

[29] F. Granato, A. Bianco, C. Bertarelli, G. Zerbi, Macromol. Rapid Commun. 2009, 6, 453.

[30] J. Xu, L. Zhu, Z. Bai, G. Liang, L. Liu, D. Fang, W. Xu, Org. Electron. physics, Mater. Appl. 2013, 14, 711.

[31] S. Peng, L. Fan, C. Wei, H. Bao, H. Zhang, W. Xu, J. Xu, Cellulose 2016, 4, 2639.

[32] J. Vilčáková, M. Paligová, M. Omastová, P. Sáha, O. Quadrat, Synth. Met. 2004, 2, 121.

[33] M.-A. De Paoli, R. J. Waltman, A. F. Diaz, J. Bargon, J. Polym. Sci. Polym. Chem. Ed. 1985, 6, 453.

[34] S. K. Dhawan, D. C. Trivedi, Bull. Mater. Sci. 1993, 5, 371.

[35] G. Nyström, A. Mihranyan, A. Razaq, T. Lindström, L. Nyholm, M. Strømme, J. Phys. Chem. B 2010, 114, 4178.

[36] Y. Li, M. Y. Leung, X. M. Tao, X. Y. Cheng, J. Tsang, M. C. W. Yuen, J. Mater. Sci. 2005, 15, 4093.

[37] S. Y. Liew, W. Thielemans, D. A. Walsh, J. Phys. Chem. C 2010, $41,17926$.

[38] K. Jradi, B. Bideau, B. Chabot, C. Daneault, J. Mater. Sci. 2012, 47, 3752.

[39] T. Takano, A. Mikazuki, T. Kobayashi, Polym. Eng. Sci. 2014, $1,78$.

[40] Z. Shi, H. Gao, J. Feng, B. Ding, X. Cao, S. Kuga, Y. Wang, L. Zhang, J. Cai, Angew. Chemie - Int. Ed. 2014, 21, 5380.

[41] D. A. Gopakumar, D. Pasquini, M. A. Henrique, L. C. De Morais, Y. Grohens, S. Thomas, ACS Sustainable Chem. Eng. 2017, 5, 2026.

[42] D. A. Gopakumar, A. R. Pai, Y. B. Pottathara, D. Pasquini, L. Carlos De Morais, M. Luke, N. Kalarikkal, Y. Grohens, S. Thomas, ACS Appl. Mater. Interfaces 2018, 23, 20032.

[43] M. Lay, J. A. Méndez, M. Delgado-Aguilar, K. N. Bun, F. Vilaseca, Carbohydr. Polym. 2016, 152, 361.

[44] K. Firoz Babu, P. Dhandapani, S. Maruthamuthu, M. Anbu Kulandainathan, Carbohydr. Polym. 2012, 4, 1557.

[45] Z. Shi, H. Gao, J. Feng, B. Ding, X. Cao, S. Kuga, Y. Wang, L. Zhang, J. Cai, Angew. Chemie - Int. Ed 2014, 21, 5380.

[46] P. Jha, S. P. Koiry, V. Saxena, P. Veerender, A. K. Chauhan, D. K. Aswal, S. K. Gupta, Macromolecules 2011, 44, 4583.

[47] H. Wang, L. Bian, P. Zhou, J. Tang, W. Tang, J. Mater. Chem. A 2013, 112, 44.

[48] J. Chen, J. Xu, K. Wang, X. Qian, R. Sun, ACS Appl. Mater. Interfaces 2015, 28, 15641. 
[49] M. H. Al-Saleh, U. Sundararaj, Carbon N. Y. 2009, 47, 2.

[50] N. G. Sahoo, S. Rana, J. W. Cho, L. Li, S. H. Chan, Prog. Polym. Sci. 2010, 35, 837.

[51] L. F. Chen, C. K. Ong, C. P. Neo, V. V. Varadan, V. K. Varadan, Microwave Electronics Measurement and Materials Characterisation, John Wiley \& Sons, West Sussex, England 2004.

[52] Y. B. Pottathara, S. Thomas, N. Kalarikkal, T. Griesser, Y. Grohens, V. Bobnar, M. Finšgar, V. Kokol, R. Kargl, New J. Chem. 2019, 2, 681.

[53] S. R. Dhakate, K. M. Subhedar, B. P. Singh, RSC Adv. 2015, 5, 43036.

[54] A. R. Pai, C. Paoloni, S. Thomas, in Nanocellulose Based Composites for Electronics, Elsevier, Amsterdam, Netherlands, p. 237.

[55] A. R. Pai, T. Binumol, D. A. Gopakumar, D. Pasquini, B. Seantier, N. Kalarikkal, S. Thomas, Carbohydr. Polym. 2020, 246, 116663.

[56] T. Tanaka, M. Kozako, N. Fuse, Y. Ohki, IEEE Trans. Dielectr. Electr. Insul. 2005, 4, 669.

[57] A. Chaudhary, S. Kumari, R. Kumar, S. Teotia, B. P. Singh, A. P. Singh, S. K. Dhawan, S. R. Dhakate, ACS Appl. Mater. Interfaces 2016, 8, 10600.

[58] T. W. Lee, S. E. Lee, Y. G. Jeong, ACS Appl. Mater. Interfaces 2016, 20, 13123.
[59] J. A. Marins, B. G. Soares, M. Fraga, D. Müller, G. M. O. Barra, Cellulose 2014, 21, 1409.

[60] B. Fugetsu, E. Sano, M. Sunada, Y. Sambongi, T. Shibuya, X. Wang, T. Hiraki, Carbon N. Y. 2008, 46, 1256.

[61] H. D. Huang, C. Y. Liu, D. Zhou, X. Jiang, G. J. Zhong, D. X. Yan, Z. M. Li, J. Mater. Chem. A 2015, 8, 2376.

[62] S. Mondal, S. Ganguly, P. Das, P. Bhawal, T. K. Das, L. Nayak, D. Khastgir, N. C. Das, Cellulose 2017, 11, 5117.

\section{SUPPORTING INFORMATION}

Additional supporting information may be found online in the Supporting Information section at the end of this article. 